\title{
IMPACTO DO PROJETO “CORDEL NO ESPAÇO ESCOLAR” NAS BIBLIOTECAS ESCOLARES DE JOÃO PESSOA-PB
}

\section{EL IMPACTO DEL PROYECTO "CORDEL EN EL ESPACIO ESCOLAR” EN LAS BIBLIOTECAS ESCOLARES DE JOÃO PESSOA-PB}

\begin{abstract}
Danielle Dos Santos Souza Belisario - daniellesouzajp@yahoo.com.br Bibliotecária pela Universidade Federal da Paraíba (UFPB).

Maria Elizabeth Baltar Carneiro de Albuquerque beth_baltar@yahoo.com.br Doutora em Letras pela Universidade Federal da Paraíba (UFPB). Professora do Departamento de Ciência da Informação da UFPB.
\end{abstract}

RESUMO

Introdução: O incentivo à leitura e disseminação da Literatura de Cordel foram os principais aspectos que nos motivaram a trabalhar o projeto "Cordel no Espaço Escolar".

Objetivo: Diagnosticar o impacto causado pelo projeto nas bibliotecas ou salas de leitura das escolas públicas da cidade de João Pessoa - Paraíba.

Metodologia: O método utilizado foi o quali-quantitativo, considerando os aspectos qualitativos - como a reflexividade do pesquisador e as opiniões dos respondentes - quanto aos aspectos quantitativos por verificar as porcentagens obtidas através da aplicação do questionário. O corpus do trabalho foi constituído por cinquenta escolas que foram beneficiadas com a doação dos cordéis. Como amostra, foram selecionadas dezesseis escolas do bairro do Cristo Redentor. Como técnica de pesquisa para coleta de dados foi utilizado o questionário.

Resultados: Constatamos que os professores trabalharam os folhetos de cordel em sala de aula e desenvolvem várias atividades além do incentivo à leitura.

Conclusões: Identificou-se que o projeto "Cordel no Espaço Escolar", teve forte influência no incentivo à leitura. Despertou nos professores e alunos a importância para valorização da cultura, ao deixar em cada escola a riqueza cultural que representa o cordel e as inúmeras atividades didáticas que podem ser realizadas com este suporte. 
Palavras-chave: Biblioteca Escolar. Literatura de Cordel. Incentivo à leitura.

\section{INTRODUÇÃO}

A Literatura de Cordel, em suas múltiplas manifestações temáticas, desperta a curiosidade e também o desejo de adentrar em um mundo de versos rimados com estrofes que instigam a imaginação de quem o escuta. Além disso, ao longo dos anos, tem sido instrumento de estímulo à prática da leitura.

O cordel tem exercido grande influência no acesso à leitura por parte dos brasileiros. No passado, se concentrava principalmente no Nordeste, nas classes sociais menos favorecidas. Atualmente tem se expandido para todas as regiões do país e sido utilizado como suporte paradidático nas escolas. Um exemplo disso é a proposta de trabalhar o cordel na biblioteca escolar a partir do projeto 'cordel no espaço escolar', desenvolvido pelo professor Manoel Belisario o qual faz exaltação da cultura nordestina e busca proporcionar a aproximação entre o aluno e a leitura.

Através dos folhetos de cordel, os saberes e a cultura são difundidos com mais facilidade. Isso acontece porque os cordéis possuem estrutura simples e textos de fácil entendimento. Os escritos contidos nos folhetos tornam as aulas mais dinâmicas, cujos temas podem ser utilizados em várias disciplinas escolares, como também incentivar o professor no desenvolvimento de atividades como: contação de histórias, peças teatrais, cinema, oficinas de desenho e na didática da aula com a leitura de folhetos sobre o assunto abordado.

O tema escolhido certifica a valorização de um dos primeiros suportes de alfabetização da população. As leituras dos folhetos, na maioria das vezes feitas pelo próprio poeta, chamavam a atenção de quem o escutava e, partir daí, surgia o interesse e a vontade de se tornar cidadãos alfabetizados.

A biblioteconomia por ser uma área interdisciplinar, apresenta um leque de assuntos - dos mais simples aos mais complexos, o que proporciona ao pesquisador trabalhar com outras áreas do conhecimento. Pensar em cordel é deixar fluir as ideias e lançar propostas que enalteçam as práticas escolares. Um espaço na biblioteca escolar ou sala de leitura que seja reservado para o cordel é uma valiosa estratégia para atrair cada vez mais a atenção dos alunos e o gosto pela leitura. 
A pesquisa teve como objetivo diagnosticar o impacto causado pelo projeto "Cordel no Espaço Escolar" nas bibliotecas ou salas de leituras das escolas públicas de João Pessoa - PB, beneficiadas pelo projeto.

A inexistência de folhetos de cordel nas escolas chama a atenção para uma problemática: os professores não trabalham as várias temáticas de que tratam o cordel em suas disciplinas o que pode ocasionar também a falta de incentivo à leitura. Cobian (2011, p. 110) enfatiza o preconceito que se tem com a literatura de cordel ao afirmar que:

Apresentar a literatura de cordel, nas escolas, não é uma tarefa fácil nem tampouco recorrente. O notório preconceito que se tem em relação à literatura de cordel fica logo evidenciado no exame de materiais didáticos, visto que muitos não abordam o cordel e a minoria que o faz, muitas vezes, focaliza essa produção de forma equivocada e preconceituosa, solicitando dos alunos, como atividade, a reescritura do texto, com a correção dos "erros gramaticais", que, como se sabe, são, na verdade, variedades de registro.

Percebe-se que a literatura de cordel ainda é pouco valorizada no ambiente escolar. Os professores limitam-se ao uso do livro didático. Menezes Neto (2008, p. 2) comenta sobre o modelo de ensino:

[...] há algumas propostas para a superação desse modelo, que se caracteriza muitas vezes por um predomínio do senso comum, com os professores apenas reproduzindo os conteúdos do livro didático, muitas vezes a única fonte de conhecimento histórico. Desse modo, professores e alunos se comportam como sujeitos passivos diante do livro.

Ainda é grande a resistência para se trabalhar o cordel, por isso a valorização desse suporte informacional continua precária. Nesse sentido, Cobian (2011, p. 111) explica:

Assim, não é difícil perceber que a literatura de cordel, rica expressão da poesia popular brasileira, ainda pouco valorizada, está quase ausente do ambiente escolar. Sabe-se que os fatores responsáveis por essa exclusão, em geral não-assumida, são inúmeros, dentre eles, está o aludido preconceito linguístico. Por isso mesmo, tendo-se em vista um ensino democrático, julga-se relevante o trabalho com essa produção literária e o estudo de suas especificidades. 
O Nordeste, representante desta cultura, precisa mantê-la viva para algo que é tão característico desta região: o cordel, veiculador de informação e saberes auxilia no processo de ensino e incentivo à leitura. Luiz Milanesi fala com propriedade sobre o ensino no Brasil, texto escrito há trinta e um anos, mas que foi um precursor da atual realidade da educação em nosso país hoje.

\begin{abstract}
Os sistemas de informação devem apoiar-se no sistema integral de ensino, permitindo um fluxo ascendente daqueles que se interessam pela investigação. Assim, a instituição criada para controlar a informação num determinado setor do conhecimento humano não será um presente pouco prático e sem uso integral, mas responderá uma exigência do meio social de onde emerge e pelo o qual é financiada. [...] A escola brasileira, por vezes, tem a aparência de uma pirâmide invertida: falta base de formação escolar mais eficiente, essa que desenvolve nos indivíduos 0 interesse pelas informações (MILANESI, 1983, p. 23).
\end{abstract}

É preciso investir na educação básica para que as crianças adquiram desde cedo o hábito pela leitura e despertem o gosto pelos estudos.

Para diagnosticar o impacto que o projeto "Cordel no Espaço Escolar" causou nas escolas da rede pública da cidade de João Pessoa-PB, foi aplicado um questionário para avaliar a aceitação do projeto e o que este proporcionou à comunidade escolar.

\title{
2 LITERATURA POPULAR
}

A literatura popular é um tipo de manifestação cultural desenvolvida pelo povo que, segundo Albuquerque (2011, p. 23), "disponibiliza o oral e o escrito como modalidades de apresentação, sendo o romance, o conto, a cantiga, entre outros, como tipicamente orais e o cordel, escrito". O folheto de cordel porque era, talvez, o mais conhecido, era acessado principalmente por aqueles que não sabiam ler e escrever e que por meio da oralidade debruçavam-se em suas histórias, pelo simples fato de escutar alguém narrando. A elite, onde o poder aquisitivo é mais acentuado tem melhores condições de apreciar e fazer cultura, mas independente de poder social, crença, etc. cada um, de acordo com o seu segmento e contexto no qual está inserido, tem um jeito e um modo diferente de expressar-se culturalmente. Para Morgão (2009), desde a Idade Média, a elite, por ser detentora do poder, tinha 
o privilégio de melhor usufruir da arte, ao contrário das classes menos favorecidas. A autora assevera que:

A cultura erudita pertencia àqueles que tinham condições de usufruílas e viver apenas de arte. Como a maioria das pessoas dessas épocas mais remotas não tinha esse privilégio, podemos dizer que a eles cabia a cultura da oralidade, sabedorias passadas de gerações para gerações. Camponeses daquela época - aqui podemos fazer uma comparação com os trabalhadores de hoje - não detinham de tal conhecimento erudito para compor grandes cânticos como os nobres, porém, não eram alheios à arte e à cultura de suas regiões (MORGÂO, 2009, p. 13).

Com o passar do tempo, a informação tornou-se acessível e aproximou-se das diversas camadas da sociedade. As classes mais pobres foram beneficiadas com o conhecimento que antes era restrito e, de fato, saberem quais os seus reais direitos, pois a cultura popular possui diferenciações da cultura de elite. Assim como afirma Albuquerque, possui características mais profundas e que se identifica com a maioria da população.

A cultura popular possui uma lógica diferenciada, um espaço de atuação próprio, um código de simbologias, singulares concepções e um tempo particular que são identificadas a cada manifestação cultural, tendo como uma das suas principais características, a formação de um grande nicho de diversidade, tornando-a mais complexa, o que não se pode dizer o mesmo da cultura de elite (ALBUQUERQUE, 2011, p. 19).

A cultura popular é mais espontânea e retrata com simplicidade todos os costumes de uma região e em específico de seu povo, é representada pela dança (maracatu, côco de roda, ciranda etc.), música (repente, cantoria etc.) e o cordel que, para Morgão (2009, p. 18), "tem como objetivo apresentar pessoas simples fazendo arte, cultura, um verdadeiro espelho de sua realidade". O cordel retrata acontecimentos da realidade e que, através da oralidade, alcança um grande número de pessoas, mesmo as que ainda são de certa forma privadas dos suportes informacionais, o folheto de cordel supre esta necessidade de informação.

A literatura popular registra através da escrita, narrativas oriundas da memória coletiva, fatos e manifestações culturais que servirão como referencial para as futuras gerações conhecerem a história e o meio no qual estão inseridos. 
Mesmo que haja mudanças no decorrer dos anos e que as pessoas desenvolvam outras maneiras de difundir sua cultura, a essência do modo e do jeito de ser sempre prevaleceram. Segundo Domingues (2011), a carga de significados que o termo cultura possui é vasta, sendo também agregadora de novos valores que fluem positivamente para o bem-estar de todos.

A cultura popular provocaria esse impacto positivo devido ao charme da palavra "popular". De certo modo, ela tem por base as experiências, memórias e tradições do povo, estabelecendo ligações com o cotidiano, as expectativas, os projetos, as esperanças e as aspirações das pessoas comuns. Todavia, isso não é tudo. O termo "popular" é polissêmico, ou seja, carrega vários sentidos e significados. De acordo com seu significado recorrente, uma cultura é "popular" porque as massas, o "povo", a valoriza bastante, comprando, lendo, escutando e consumindo (DOMINGUES, 2011, p. 13).

Este conceito chama atenção pelo esclarecimento e reflexão acerca da palavra cultura, para as tradições que passam de geração a geração; os costumes característicos de cada lugar e a influência da cultura de massa para - o comprar, consumir etc. Portanto, é preciso estar alerta sobre qual cultura nos enveredarmos, alguns exemplos são - a música, dança, literatura, cinema e as manifestações populares que são próprias de cada região.

Ao discorrer sobre literatura popular, destacamos a literatura de cordel que tem sua predominância na região nordeste.

\subsection{Literatura de Cordel}

A origem da literatura de cordel conforme muitos autores relatam é da Península Ibérica - Portugal e Espanha do século XVI. Para Albuquerque (2011, p 25), "não existe consenso entre os estudiosos de literatura popular quanto à origem do cordel no Brasil, entretanto, é inegável a influência do cordel português na constituição do folheto brasileiro [...]". Sobre a literatura de cordel, Morgão (2009, p.12) afirma: "dando um enfoque maior para a literatura de cordel, cabe dizer que sua gênese deu-se na União Ibérica, com uma voz mais acentuada em terras lusitanas".

Cada país tem uma variante para os folhetos, ou seja, uma denominação própria. Em Portugal são chamadas folhas soltas ou folhas volantes, na Espanha são denominados Pliegos Sueltos, na França são conhecidos por litterature de 
colportage, na Inglaterra são os catchennier, nas Américas os compuestos etc. São muitas as nomenclaturas dadas ao folheto, pois, conforme cada país seus textos, representam as peculiaridades de cada lugar.

A literatura de cordel adentrou no Brasil pela região Nordeste, sendo disseminada oralmente nas feiras de ruas e sua comercialização também se expandiu para outros lugares como mercearias, livrarias, lojas, barracas etc. Os folhetos foram introduzidos no Brasil oralmente pelo cantador Silvino Pirauá de Lima, e Leandro Gomes de Barros com sua organização sistemática foi responsável pelas primeiras impressões de folhetos de cordel no Brasil. Este fato ocorreu na metade do século XIX, como cita Teixeira (2008, p. 13),

[...] do século XIX das primeiras impressões de folhetos de cordel. O precursor foi o poeta Leandro Gomes de Barros (1868-1919) e o primeiro folheto localizado é deste poeta e data de 1893. A partir daí, a literatura de cordel passou a ser, além de cantada, também escrita.

Leandro Gomes de Barros foi o poeta que mais se destacou na produção de folhetos. Nasceu na cidade de Pombal e depois residiu em Teixeira, ambas situadas no interior da Paraíba. Seus cordéis inspiraram outros poetas a seguirem a rima e a métrica literalmente. Hoje não se pode falar em literatura de cordel sem mencionar Leandro. Sua estrutura como menciona Albuquerque (2011, p. 26) é a seguinte:

[...] é impresso, de 8 a 16 páginas em sua maioria, no tamanho 15 a $17 \mathrm{~cm}$. $\times 11 \mathrm{~cm}$. e impressos com capas ilustradas com xilogravuras, em serviços tipográficos artesanais, criados pelos próprios poetas e contra-capas com pequenos textos de classificados, anúncios eleitorais, fotos e chamadas para os próximos folhetos do próprio autor.

É um suporte informacional feito artesanalmente pelos poetas despertou também o interesse de algumas editoras como Tupynanquim, Luzeiro, Coqueiro, entre outras na edição destes folhetos.

O folheto de cordel objetiva transmitir poeticamente os fatos da atualidade, homenagear, sugerir e aguçar o senso crítico de seus leitores. A proposta de levar o cordel para escola é apresentar os vários tipos de leitura aos alunos e sua riqueza cultural. Silva enfatiza como o cordel é eclético, atingindo um grande público de variados gostos. 
A Literatura de cordel é um tipo de poesia popular, originalmente oral, ainda muito comercializado por conta de seu valor poético e, muitas vezes lúdico, que narra histórias reais atuais e passadas, disseminando valores, hábitos e costumes regionais que são verdadeiras relíquias de uma cultura, por muitos considerados menor, mas que representa um valor incalculável no campo da culinária, da música, do artesanato e da identidade nacional. Estes livretos que preservam a cultura popular geralmente têm sobrevivido a mudanças ao longo das décadas sem perder suas características tradicionais (SILVA, 2012, p. 24).

O cordel é um dos elementos característicos da cultura popular, por manter viva a tradição de um povo, como também motivo de grandes celebrações em diversos segmentos da sociedade, pois sua rima expressa a vivência e o cotidiano das pessoas que se deslumbram ao ouvir. Um dos meios mais antigos de alfabetização da população é o cordel - ao transmitir informações sobre os diversos acontecimentos e despertar o interesse de todos pela leitura, este suporte é capaz de proporcionar aos alunos o primeiro contato com um mundo de saberes e descobertas. Conforme Alves,

\begin{abstract}
Abordar a presença da Literatura de Cordel em sala de aula implica refletir, entre outras coisas, sobre as concepções de leitura, literatura e ensino postos em prática no cotidiano das escolas. Seria propor uma forma de estimular os alunos a enxergarem o que há por trás dessas produções textuais, não só no que diz respeito ao texto em si, mas com relação às vozes que ele traz consigo. Vozes essas capazes de expressar questões morais, políticas, sociais, econômicas e culturais (ALVES, 2008, p.108).
\end{abstract}

A importância da literatura de cordel para o ensino proporciona condições satisfatórias tanto para o professor como o aluno, pois é possível desenvolver um trabalho conjunto de ensino e aprendizado. As escolas, através de seus professores, podem ter aliados fortes e versáteis para trabalhar nas disciplinas de ensino fundamental e médio.

A leitura dos folhetos por ser simples e atrativa para os alunos favorece a sua aplicação em sala de aula. A Secretaria de Estado da Educação de Goiás comenta sobre a diversidade textual e o ato de ler.

Resgatar a leitura como experiência lúdica e prazerosa, por meio da diversidade textual e dos suportes multimídias, além da dinamização de bibliotecas e salas de leitura, transforma a leitura no ambiente escolar em prática social e possibilita, ao mesmo tempo, a expansão e a inserção do indivíduo na sociedade, pois o ato de ler é mais do 
que simplesmente decifrar o código de uma língua (GOIAS. SECRETARIA DE ESTADO DA EDUCAÇÃO, 2009, p. 59).

Com este propósito, as escolas precisam desenvolver suas ações, investir em seus alunos, protagonistas principais do ambiente escolar. Para isto, devem disponibilizar suportes que favoreçam e estimulem o aprendizado. Um dos suportes é o cordel, em que os poetas dão a sua contribuição ao escrever sobre vários temas que abordam a educação.

\section{O BIBLIOTECÁRIO COMO MEDIADOR DA LEITURA NA BIBLIOTECA ESCOLAR}

A informação está presente em todos os seguimentos da sociedade. Conforme Barreto (1994, p. 2), "a informação, quando adequadamente assimilada, produz conhecimento, modifica o estoque mental de informações do indivíduo e traz benefícios ao seu desenvolvimento e ao desenvolvimento da sociedade em que ele vive". Estas competências vão progredindo com o passar do tempo, as descobertas e o aprendizado de cada dia, vão colorindo os sonhos de criança e enchendo-as de esperança para o novo. Com o aperfeiçoamento da fala surge à escrita, ambas são peças fundamentais para o aprimoramento do ensino. Silva (2012, p. 5) destaca que a fala sobressai à forma escrita.

[...] a escrita constitui-se como uma representação simbólica da linguagem falada, porém não consegue ser totalmente fiel a ela, pois as possibilidades do uso da linguagem falada são inúmeras, e a escrita tenta apenas aproximar-se desse universo.

Inferimos, a partir da citação, que o que liga a fala à escrita é a leitura, pois através delas que a pronúncia é feita adequadamente e a forma de escrever obedece aos padrões da norma culta. As escolas têm o dever de oferecer a seus alunos uma variedade de textos, como destaca Ribeiro,

$\mathrm{Na}$ escola, crianças e adolescentes precisam ter contato com diferentes textos, ouvir histórias, observar adultos lendo e escrevendo. Precisam participar de uma rotina de trabalho variada e estimulante e, além disso, receber muito incentivo dos professores e da família para que, na idade adequada, aprendam a ler e escrever (RIBEIRO, 2006, p. 5). 
A necessidade de aperfeiçoar e contribuir para o desenvolvimento da criança direciona os pais a matricularem seus filhos em uma escola que corresponda às suas expectativas, tanto nas práticas pedagógicas como em seu quadro de profissionais. Sobre este assunto, Pinto e Oliveira ressaltam que,

No momento atual são dados papéis renovados para os componentes da comunidade escolar, tanto gestores, pedagogos, professores, e demais profissionais envolvidos com a formação dos alunos, assim como seus espaços pedagógicos, entre eles a biblioteca, esta última com o dever de enfatizar em sua prática diária o uso da criatividade no desenvolvimento de ações que sirvam como indicadoras da transformação que venha ocorrer, possibilitando a todos os sujeitos supracitados condições de acesso à informação e ao conhecimento (PINTO; OLIVEIRA, 2013, p. 5).

É notório que as atividades realizadas em parceria com professores, diretores e bibliotecários resultaram em benefícios principalmente para o aluno, pois 0 bibliotecário entre suas inúmeras funções é um agente cultural dinamizador das atividades escolares como certifica Munhoz (2010, p. 9) "O bibliotecário enquanto agente cultural se torna elemento imprescindível para manutenção dessas atividades, expandindo seu contexto tradicional - a biblioteca". Munhoz (2010) ainda exemplifica estas atividades com "à hora do conto, importância da leitura e mostra de livros". São estas ações promovidas pelos bibliotecários que dão visibilidade à biblioteca e desperta o interesse dos alunos para pesquisas, leituras e uso deste espaço como um todo.

A palavra biblioteca parece até estranha para algumas pessoas, infelizmente por questões sociais ou mesmo de desinteresse, ainda são poucos os que sabem da sua importância. A biblioteca precisa ganhar destaque, desenvolver atividades que despertem a atenção de todos a sua volta, a base é a biblioteca escolar onde tudo começa, as crianças se encantam com os livros e as histórias que escutam. Araújo e Sales (2011, p. 563) comentam,

Portanto, entende-se que a existência de uma biblioteca escolar ativa é um fator fundamental, pois é um instrumento que pode auxiliar no processo de ensino-aprendizagem, por isso as ações ligadas a ela precisam ser dinâmicas, considerando que este é o primeiro tipo de biblioteca que a criança frequentará, logo, este primeiro contato precisa ser amigável para que ela se torne uma frequentadora assídua. 
A vivência com os livros capacitará as crianças para sucessos futuros, pois o gosto pelo saber e a influência que a biblioteca escolar proporciona sempre os conduzirá para conquistas satisfatórias. Infelizmente muitas coisas precisam ser feitas por parte dos bibliotecários, diretores, supervisores, professores e governantes. Além de palavras e promessas vazias, é preciso colocar em prática o que realmente é importante como reflete Russo e Souza (2013, p. 2) sobre biblioteca escolar:

A biblioteca escolar (BE), apesar de se constituir em um dos segmentos mais antigos das bibliotecas brasileiras, ainda não possui um lugar consolidado em nossa sociedade. O resultado desta desvalorização se encontra pautado na falta de bibliotecários nas escolas públicas e privadas, o que muitas vezes se justifica na oferta de baixos salários e, em consequência disso, no estabelecimento de leigos gerenciando a biblioteca.

Muito se fala sobre a biblioteca escolar e os seus benefícios para sociedade, pena que as atitudes para a construção e valorização deste espaço são poucas. É necessário lutar mais. Essa luta deve partir, em especial, dos profissionais Bibliotecários que são âncoras para o sucesso de uma biblioteca. Fonseca (2007) categoriza as bibliotecas conforme a faixa etária e tipos de usuários: bibliotecas infantis, escolares, universitárias, especializadas, nacionais, públicas e do Brasil, sendo que para cada uma existe uma definição plausível e que justifica sua importância. Independentemente do tipo e tamanho, é necessária a atuação de um profissional nestes espaços. Macedo $(2005$, p. 314$)$ reitera que,

[...] o profissional Bibliotecário deveria ser requisitado ou se impor, munido de conhecimentos e habilidades de comunicação, para dialogar com arquitetos, comunicadores visuais e especialistas em informática e, ainda, com o diretor da escola, no tocante a verbas necessárias para a manutenção da biblioteca, ou para as devidas mudanças e transformação de uma biblioteca escolar tradicional para biblioteca moderna, até informatizada, e já vinculada a redes digitais e uso de micros e recursos da internet.

Para Castro Filho e Coppola Junior (2012, p. 32), "um fato alarmante que observamos com relação à infraestrutura e ao organograma das escolas públicas é a ausência de bibliotecas escolares e de profissionais habilitados, limitando a formação integral dos alunos", pois impossibilitará o seu contato com os livros e, consequentemente, resultará uma leitura precária e deficiente. 
A Biblioteca escolar é o alicerce para a formação do aluno, pois o prepara para a academia e é fundamental para sua formação como cidadão. Nesse contexto, Macedo (2005, p. 425) argumenta que,

\begin{abstract}
A biblioteca escolar (BE) propicia informação e ideias fundamentais para o sucesso de seu funcionamento na atual sociedade, baseada na informação e no conhecimento. A BE habilita os estudantes para a aprendizagem ao longo da vida e desenvolve sua imaginação, preparando-os para viver como cidadãos responsáveis.
\end{abstract}

Com o aparato da biblioteca escolar é possível melhorar as condições de ensino e desenvolver no aluno o senso crítico para expor suas ideias com conhecimento sobre diversos assuntos. O bibliotecário irá atuar como mediador da informação, pois das diversas formas de atuação deste profissional esta é uma das mais importantes.

O bibliotecário desenvolve várias atividades como: serviço de referência; processos técnicos - catalogação, classificação e indexação para que o acervo flua normalmente. Também é um agente cultural disseminador da informação, entre outras funções. Mas, para o desenvolvimento destas atividades, é preciso que a escola contrate um profissional adequado, assim como afirma Almeida (2012, p. 475),

[...] é necessário que na escola ofereça uma biblioteca com um bom acervo e também, que a mesma conte com um profissional bibliotecário. Não é suficiente que na escola tenha uma biblioteca bem estruturada se esta não contar com um profissional comprometido para desenvolver suas funções. As atividades inerentes ao bibliotecário nas bibliotecas escolares são importantes para que se torne, de fato, parte integrante e ativa das escolas. Ao bibliotecário cabe uma grande parcela da responsabilidade pelos resultados das ações realizadas dentro da biblioteca.

Todo e qualquer trabalho só será bem desenvolvido com um profissional habilitado, pois ele saberá as peculiaridades de sua área e contará também com o conhecimento adquirido após anos de estudos. Em uma biblioteca a pessoa mais indicada para gerenciá-la é o Bibliotecário cuja função mais importante a de formadores de leitores, principalmente nas bibliotecas escolares onde a criança inicia seus estudos e se encanta com as histórias infantis e o colorido dos livros. Para enfatizar, Araújo e Sales (2011, p. 572) destacam as, 
[...] inúmeras habilidades inerentes ao bibliotecário formador de leitores como: ser comunicativo, estar sempre bem informado, ser articulado, dinâmico, conhecer as preferências dos alunos e seu universo. Também [...] características como a perseverança, ser convincente, conhecer os livros de literatura, gostar do que faz, gostar de criança e ter poder de alteridade. Com relação a esta última habilidade, entende-se como fator fundamental ter a capacidade de se colocar no lugar do outro, pois é desta forma que saberemos como tratar o próximo, a forma de falar com uma criança de cinco anos, por exemplo.

A escola é o lugar ideal para demonstrar as boas ações, os exemplos contribuirão para o desenvolvimento e a boa cidadania dos alunos. Para Castro Filho e Coppola Junior,

O bibliotecário que conseguir aproximar os alunos da biblioteca e da informação, bem como conquistar a confiança dos professores e da direção pedagógica, divulgando as potencialidades de sua unidade de informação perante a comunidade escolar, atingirá os objetivos institucionais e sociais da biblioteca escolar (CASTRO FILHO; COPPOLA JUNIOR, 2012, p. 36).

Com empenho e dedicação, será possível uma integração maior com todos da escola, para o incentivo da leitura e também despertar no aluno o sentimento de valorização pelo livro e o gosto de estar em contato com os demais itens da biblioteca.

Sobre o acesso à leitura, Ferreira e Santana (2013, p. 2) comentam,

É através do acesso á leitura e à informação, que o homem pode ampliar, transformar e enriquecer sua própria experiência de vida. A leitura de diversificados produtos culturais são instrumentos em que podemos resgatar valores, ajudando o leitor a descobri-los e vivenciá-los no dia-a-dia.

São vários os tipos de leitura. Cada uma com um atrativo diferenciado para conquistar o leitor e fazê-lo se apaixonar pelas histórias contidas nos livros, pois este suporte oportuniza estes momentos. Importante também é preparar um espaço para leitura, onde o usuário sentirá que está sendo bem acolhido. Nesse sentido, Pereira justifica que,

O ideal é que a escola tenha um local destinado ao armazenamento de livros e de outros suportes impressos que permita aos alunos vivenciar a experiência da leitura em um espaço privilegiado como a biblioteca ou sala de leitura (PEREIRA, 2006, p. 9). 
O contato desde a infância com os livros proporciona melhores condições de desenvolvimento escolar, ajuda o aluno nas atividades extraclasses e melhora a comunicação e escrita. $\mathrm{O}$ incentivo da família e atenção dos pais é fundamental para o aprimoramento da leitura. As crianças se sentem confiantes e o seu desempenho melhora. A escola será o complemento da educação recebida em casa, onde os valores e princípios familiares são transferidos para os filhos desde cedo. Neste processo, em que a escola e a família são integrantes principais da educação, a biblioteca escolar precisa se fazer presente e auxiliar na dinâmica de ensino. Para Campello (2012, p. 36):

\begin{abstract}
A aprendizagem por meio da biblioteca escolar é influenciada por uma variedade de fatores (recursos, estrutura organizacional, propostas pedagógicas) e atores, como professores, administradores e estudantes, isto é, pela "cultura escolar" que compõe o contexto da escola.
\end{abstract}

A biblioteca escolar precisa ganhar destaque, ser valorizada principalmente pelas políticas voltadas para a educação, em beneficio e melhoria de toda comunidade escolar.

A Lei №12.244/10, sancionada pelo ex-presidente Luiz Inácio Lula da Silva, prevê a criação de bibliotecas em todas as escolas do país até 2020. Mesmo com aprovação da lei são muitos os problemas enfrentados. Sobre este aspecto, Castro Filho e Coppola Junior (2012, p. 31) explicam que "diante das limitações enfrentadas pela biblioteca escolar, uma esperança começa a se desenhar, em 24 de maio de 2010, entrou em vigor a Lei $n^{\circ}$ 12.244, que dispõe sobre a universalização das bibliotecas nas instituições de ensino no país". Diante do exposto, Silva (2011, p. 509), destaca que é preciso união dos envolvidos para fortalecimento da lei.

[...] a união política, profissional e acadêmica dos órgãos biblioteconômicos (Conselhos, Associações, Sindicatos e cursos de graduação) poderá efetivar um processo de consciência de classe e senso de progressão da construção de uma nova mentalidade social de biblioteca escolar.

É preciso empenho e dedicação para lutar por melhorias que fortaleçam a lei. Com a criação de bibliotecas em todas as escolas e também com a contratação do profissional bibliotecário, ganhará vida o que hoje está apenas no papel. Com a aprovação e a perspectiva para a implantação e aplicação da Lei ㄲo12.244/10 num 
prazo máximo de dez anos, é inaceitável a construção de escolas sem a menor preocupação de se pensar em um lugar para biblioteca. Para Silva (2011), era preciso ter incluído na lei artigos que fortalecessem ainda mais a exigência do cumprimento da mesma tanto para os órgãos públicos como privados.

Acredito que o princípio fundamental de norteamento político e institucional para a aplicação da Lei 12.244/10, seria ter incluído nela, artigo que delimitasse ao Poder Público uma porcentagem mínima do orçamento destinado à biblioteca de suas escolas, e a mesma exigência aos empresários da educação, procurando desta forma garantir investimento na biblioteca (estrutura física, organização, sistema, contratação de bibliotecários e de outros profissionais, implementação de serviços e outros), conforme suas atribuições. No caso do descumprimento, os gestores, quer públicos, quer privados, deveriam pagar multa (SILVA, 2011, p. 509).

A referida lei possui lacunas em seus artigos que deveriam especificar mais 0 seu cumprimento, ao impor multas principalmente para os gestores municipais e estaduais ao seu descumprimento quando constrói escolas, mesmo depois de sancionada a lei sem deixar um lugar reservado para biblioteca.

No artigo segundo da Lei no 12.244/10 (BRASIL, 2010), é especificado o conceito de biblioteca escolar "Para os fins desta Lei, considera-se biblioteca escolar a coleção de livros, materiais videográficos e documentos registrados em qualquer suporte destinados a consulta, pesquisa, estudo ou leitura". Inicialmente é com esta proposta que é preciso estruturar uma biblioteca escolar. E o prazo máximo para vigorar a lei é descrito no artigo terceiro.

Os sistemas de ensino do País deverão desenvolver esforços progressivos para que a universalização das bibliotecas escolares, nos termos previstos nesta Lei, seja efetivada num prazo máximo de dez anos, respeitada a profissão de Bibliotecário, disciplinada pelas Leis no 4.084, de 30 de junho de 1962, e 9.674, de 25 de junho de 1998 (BRASIL. 2010).

É preciso mais mobilizações de bibliotecários, órgãos de classe, governantes, professores e diretores para que a sociedade visualize e também participe ao solicitar para escola de seus filhos uma biblioteca que atenda a proposta do currículo escolar.

Os bibliotecários precisam ser versáteis e agir como profissionais competentes na hora de colocar em prática suas habilidades, uma vez que a teoria 
vista na universidade é bem diferente da realidade que se encontra na hora de exercer a função. É fundamental realizar leituras para aprofundar os conhecimentos e também especializar-se na área de atuação. Conforme menciona Rodrigues,

O caminho para o conhecimento em toda e qualquer área de estudo passa pelo acesso e prática contínua da leitura. É importante, pois, observar que o ato de ler contém em si o princípio da totalidade e da dinamicidade que envolve o próprio movimento da realidade humana e social. Nesse sentido, homens e mulheres como seres sociais, ao longo da história produzem saberes e cultura, interpretando-os e reinterpretando-os à luz de um conhecimento mais sistematizado ou fundamentado em um saber de experiência, construídos no cotidiano (RODRIGUES, 2012, p. 2).

É a vivência do dia a dia e o amor pela profissão que capacitam o profissional bibliotecário, em especial os da biblioteca escolar, a compartilhar suas experiências e contribuir para o crescimento dos que necessitam de seu auxílio - na pesquisa, nos estudos e nas atividades didáticas de um modo geral.

É importante que os alunos reconheçam a biblioteca como um espaço agradável, que preencha suas expectativas. O bibliotecário possui competências necessárias para atrair a atenção do aluno e incentivá-lo à leitura, inclusive trabalhar os cordéis na biblioteca com os alunos. As opções de atividades são vastas, como menciona Araújo e Sales (2011, p. 567),

À hora do conto ainda é reconhecida como uma das principais atividades de incentivo à leitura nas bibliotecas escolares. Ouvir histórias, além de despertar a imaginação, instiga a criança a conhecer novas histórias ou até mesmo a querer conhecer o livro que foi lido na contação de histórias.

Existe um leque de possibilidades para trabalhar a prática da leitura, através da conscientização primeiramente dos professores e em seguida a dos alunos. $O$ bibliotecário deverá fazer uso de todas as ferramentas e estratégias que possui para o incentivo à leitura como - à hora do conto, oficina de leituras, concurso de literatura infantil, troca de livros, sarau poético, entre outros. O desenvolver deste trabalho será, acima de tudo, uma parceria de todos da escola para despertar a importância do ato de ler. 
O bibliotecário contribuirá para o incentivo à leitura ao instruir alunos e demais usuários não apenas a ler, mas a compreender o que leem para que assimilem o conteúdo e reflitam sobre ele.

\subsection{O Cordel e a Prática da Leitura}

Os textos indicados para as crianças precisam ser acima de tudo atraentes ao olhar. O primeiro contato das crianças com os livros geralmente são as ilustrações presentes nos livros infantis, levando-as ao mundo da fantasia e imaginação. As ilustrações são a primeira forma de leitura que as crianças fazem, ao narrar histórias a partir das imagens contidas no texto.

Falar de leitura sem mencionar a biblioteca e vice-versa, torna-se algo desconexo haja vista um complementar o outro. Esta união é fortalecida e ganha visibilidade a partir da atuação do bibliotecário, pois é o principal mediador entre a informação e o leitor. Almeida (2012, p. 476) ressalta que "o mediador precisa fazer com que a informação chegue ao leitor e tenha sentido para que ele possa transformá-la em conhecimento". Mediar à informação é proporcionar aos usuários a leitura adequada e de sua preferência, ao indicar obras que contenham o assunto desejado para a pesquisa.

O cordel poderá ser um forte aliado na prática da leitura. Embora não sejam tão atrativos com ilustrações como são os livros, devido suas características. São de fácil assimilação, já que seus textos são curtos e versam sobre vários temas, além de ter uma linguagem simples e clara, podendo assim ser trabalhada em sala de aula. Segundo Alves (2008, p. 6), o cordel,

[...] pode ser usado como um meio, um recurso a mais para a interlocução do aluno com a sociedade. O cuidado que se deve ter é de apenas não tomar esse trabalho na escola como um mero pretexto para uma abordagem puramente gramatical ou mesmo literária, mas sim discuti-lo em toda a sua riqueza, [...] o que serve de ponto de partida para a discussão dos problemas sociais, históricos, políticos e econômicos do nosso país.

Uma boa opção para prática da leitura são as oficinas sobre cordel, pois incentiva o aluno a realizar pesquisas e simultaneamente leituras. 


\section{CAMINHO METODOLÓGICO}

$\mathrm{Na}$ pesquisa foi utilizada a abordagem quali-quantitativa por se tratar de um estudo que envolverá aspectos como - a reflexividade do pesquisador; exploração do fenômeno estudado; os anseios, expectativas e opiniões dos respondentes. E quanto aos aspectos quantitativos verificaram-se as porcentagens obtidas através da aplicação do questionário sobre as perguntas indagadas sobre o projeto "Cordel no espaço escolar".

Para o desenvolvimento da pesquisa, foi necessário definir o instrumento de coleta de dados: o questionário que foi idealizado a princípio para ser aplicado em dezesseis escolas, das cinquenta selecionadas pelo projeto, mas em três escolas não foi possível sua aplicação, pois alegaram que não tinha conhecimento sobre o projeto. Por este motivo foi aplicado em apenas treze escolas.

Antes da aplicação do questionário foi realizado um pré-teste em três escolas no período de 25 a 27 de novembro de 2013, para testar a compreensão das perguntas.

\section{O PROJETO CORDEL NO ESPAÇO ESCOLAR}

O projeto Cordel no Espaço Escolar surgiu após a observação do poeta e cordelista Manoel Messias Belisario Neto, que através de sua experiência em sala de aula como professor de português de escolas públicas da cidade de João Pessoa e Alhandra - Paraíba, identificou a necessidade de utilizar os folhetos de cordel como recursos de ensino. O objetivo do projeto é possibilitar aos alunos o acesso à Literatura de Cordel, como também sugere aos professores de língua portuguesa que elaborem atividades com os folhetos, podendo ser: leitura, interpretação de texto, estudo da gramática, poesia, rima, métrica e a história da literatura de cordel. Estas práticas seriam aprimoradas nas bibliotecas e salas de leituras, em parceria com Bibliotecários e Professores.

A partir da sua percepção sobre a inexistência dos folhetos, o professor poeta começou a trabalhar o cordel em sala de aula, como proposta de dinamizar os conteúdos que precisavam ser aplicados em sala. Por serem os folhetos de cordel uma fonte de informação de precioso uso, Gaudêncio enfatiza, ao dizer: 
É visto que os folhetos são de fato uma fonte de informação real que de uma maneira ou de outra tem incansavelmente contribuído para ajudar no processo de educação continuada, iniciação à instrução, por motivar a descoberta do lúdico e do imaginário junto às camadas populares em especial (GAUDÊNCIO, 2010, p. 4).

Com esta perspectiva, é que a inquietude de professor e também cordelista foi intensa o bastante para não se satisfazer apenas com o trabalho que já vinha desenvolvendo. Era preciso divulgar a literatura de cordel para mais pessoas. Assim como é ressaltado nas palavras de Silva.

A necessidade de repassar a cultura de um povo para seus descendentes vai além da disseminação de informação sobre hábitos e valores; ela é a principal responsável pela existência dessa comunidade. [...] Uma das funções da literatura é, pois, dar acesso ao universo cultural do grupo onde está situado (SILVA, 2006, p. 218).

Com o objetivo de colocar em prática este desejo, alçou voo e foi em busca de sua realização. Após pesquisas na internet, para participação em concursos literários, surgiu também a ideia de fazer um projeto para o prêmio "Mais Cultura de Literatura de Cordel", lançado pelo Ministério da Cultura - MINC no ano de 2010, com o objetivo de distribuir cordéis em cinquenta escolas de João Pessoa - PB.

O MINC, no decorrer destes anos, foi aperfeiçoando suas iniciativas para valorizar a cultura. Criou também vários programas como - mais cultura, o cultura viva, o vale cultura e o cinema perto de você. São estas iniciativas que valorizam o artista e oferta a sociedade o acesso para participar e prestigiar a cultura brasileira. Após o processo de inscrições, o MINC divulgou o resultado dos projetos selecionados e o projeto "cordel no espaço escolar" estava entre os contemplados.

O projeto na íntegra foi idealizado inicialmente com uma proposta de distribuir 80 cordéis em 50 escolas, o que totalizava 4.000 folhetos e uma doação para 0 proponente do projeto de 1.500 folhetos. O proponente poderia fazer uso deste material e trabalhá-lo como desejasse.

\subsection{O Projeto em Execução}

Quando os folhetos estavam todos confeccionados e separados pelos respectivos títulos, foi feita a distribuição deste material nas escolas selecionadas, através de uma listagem no site do governo municipal e estadual, com o objetivo de 
abranger o maior número de bairros da cidade de João Pessoa - PB. Cumpria-se a proposta do projeto - distribuir os cordéis para serem trabalhados conforme a criatividade de cada professor. O critério de seleção das escolas foi atingir o maior número possível de escolas do bairro do Cristo Redentor onde reside o cordelista e o restante dos folhetos foram divididos entre as escolas do Estado e do município de João Pessoa - PB.

\section{ESCOLAS CONTEMPLADAS COM O PROJETO}

A cidade de João Pessoa possui atualmente, conforme informação das Secretarias de Educação do Município e do Estado, 95 escolas municipais e 119 escolas estaduais, totalizando 214 escolas públicas. O projeto Cordel no espaço escolar abrangeu escolas municipais e estaduais.

$O$ universo da pesquisa foi composto por 50 (cinquenta) escolas que foram contempladas com os 56 folhetos de cordel doados pelo projeto. A intenção maior foi expandir a literatura de cordel na sala de aula.

Para avaliar o impacto do projeto cordel no espaço escolar, utilizou-se uma amostra de 13 (treze) escolas do bairro do Cristo onde reside o poeta. Foi aplicado um questionário com dezessete questões sobre o projeto, sendo quatorze de múltipla escolha e três abertas.

A aplicação dos questionários nestas escolas foi de grande importância para o desenvolvimento da pesquisa. Embora com apenas um ano e nove meses da data da entrega dos cordéis nestes estabelecimentos de ensino, percebeu-se um vácuo em algumas escolas, entre a doação dos folhetos e as atividades trabalhadas. Das escolas visitadas para aplicação do questionário, não foi possível coletar dados em três escolas.

\section{IMPACTO DO CORDEL NAS ESCOLAS}

Ao se debruçar sobre a pesquisa e sair a campo para aplicar o questionário nas dezesseis escolas do bairro do Cristo, na cidade de João Pessoa - PB, foi possível verificar diversas situações como - organização, infraestrutura e a participação de alunos e professores no desenvolvimento do projeto. 
As escolas visitadas possuem salas de leitura, nenhuma foi denominada de biblioteca pela inexistência do profissional bibliotecário neste espaço. Algumas começaram a funcionar recentemente e a maioria é aberta em apenas um dos horários, os outros turnos só têm acesso através do professor com autorização da diretoria para pegar livros e emprestar a seus alunos. É perceptível que em algumas escolas como as escolas municipais Américo Falcão e Francisco Pereira da Nóbrega, as salas de leitura são bem estruturadas com um grande número de livros paradidáticos, cuja organização é feita por assuntos. Mas não é feito na escola algum movimento que caracterize e dê visibilidade a este espaço, que possui riquezas incontestáveis para toda educação. É visível e de extrema necessidade um profissional bibliotecário para dar o devido reconhecimento à biblioteca escolar.

Aos folhetos do projeto "Cordel no espaço escolar", doados às escolas, um cartaz e um folder explicativo sobre o mesmo e como utilizá-lo, não foi dado o devido valor. Comprovação para isto está no fato de em três escolas não ter sido possível aplicar o questionário, por causa da ausência de informações entre funcionários antigos e atuais. $\mathrm{O}$ que deu a entender é que as atividades são desenvolvidas à medida que se há uma cobrança prévia do material fornecido. Não basta apenas doar e explicar o que fazer, é preciso também, deixar claro que será feito uma prestação de contas sobre o material recebido, pois infelizmente não consciência do real valor nos dos processos de práticas educativas.

No decorrer das visitas as escolas, foi perceptível a falta de comunicação entre os turnos. Como os folhetos foram entregues à escola no horário da manhã, a equipe da tarde não tem conhecimento do material e as que têm dizem que foi trabalhado com uma determinada faixa etária e série. O desencontro de informações se torna imperdoável por se tratar de uma escola.

Mesmo com a distorção de informações, percebeu-se que os professores fizeram uso deste material. Uma pequena parcela os dinâmicos desenvolveu atividades que exploraram a riqueza dos cordéis em suas aulas. Os demais professores apenas auxiliaram nos trabalhos que envolvessem toda a escola.

\subsection{Análise e Interpretação dos Resultados}

Com as visitas realizadas nas escolas para identificar o impacto que o projeto "Cordel no espaço escolar" causou nestes ambientes de ensino e tendo como instrumento de coleta de dados o "questionário", foi possível avaliar o 
comportamento das escolas sobre cada uma das questões indagadas. O que foi contraditório ao longo das visitas foi a justificativa de um respondente ao afirmar que não tem conhecimento do projeto. O que se pode pensar é que esta pessoa não estava na escola no período da entrega, nem tampouco procurou conhecer o seu ambiente de trabalho.

O questionário foi aplicado aos professores que desenvolvem atividades com o cordel em sala de aula, pelo fato de não existir o profissional bibliotecário e a sala de leitura permanecer fechada na maior parte do tempo.

Através dos dados coletados, fez-se uma análise das respostas, de acordo com os objetivos da pesquisa, que foram assim especificados:

Entre os respondentes, o maior percentual foi 0 do sexo feminino correspondendo a $92,3 \%$, em relação ao do masculino com $7,7 \%$. Percebeu-se que as mulheres são maioria nos estabelecimentos de ensino. São elas as responsáveis pela educação das crianças, logo nas primeiras séries do ensino infantil, o que justifica também o número populacional ser maior em relação aos homens.

As pessoas de mais idade por trazer uma carga de experiência ao longo dos anos estão mais presentes nos ambientes de ensino, o que não quer dizer que os jovens também não estejam, aos poucos, conquistando estes espaços.

O nível de escolaridade dos respondentes atingiu as expectativas esperadas, uma vez que 92,3\% tem nível superior. Esta questão permitiu que os respondentes mencionassem que tem mais de uma formação superior entre elas estão: pedagogia, letras, biblioteconomia, educação artística, psicopedagogia e comunicação social. O profissional Bibliotecário não exerce a função, atua como professor de ensino fundamental. Todos os respondentes são professores, mas por não ter na escola um bibliotecário, são eles que trabalham os cordéis em suas aulas e faz a divulgação dos mesmos.

A maioria dos respondentes com 38,5\% trabalha há algum tempo na escola. São professores que trabalham com a literatura de cordel, incluindo os cordéis que foram doados pelo projeto.

Dos treze respondentes, apenas uma pessoa representando 7,7\% não conhece o projeto Cordel no espaço escolar, mas, por ficar na sala de leitura da escola no turno da tarde, respondeu o questionário.

Os respondentes consideraram importante o projeto com 61,5\% afirmando um conceito ótimo sobre sua importância e 38,5\% mencionando que o projeto foi bom. 
Isto significa que projetos desta natureza precisam ser desenvolvidos cada vez mais para valorização da biblioteca e incentivo à leitura.

O impacto do projeto foi consideravelmente bom para as escolas com $61,5 \%$. Ficou claro que o projeto foi bem aceito pelas escolas como incentivo à leitura.

A percepção dos alunos sobre os folhetos correspondeu a $61,5 \%$, o que demonstrou que o folheto de cordel incentiva a criatividade, como também o gosto pela leitura. As notícias divulgadas pela escola atraem a atenção dos alunos e estes são impulsionados a se envolverem melhor com as atividades realizadas na escola.

Os respondentes foram unânimes ao afirmarem que as escolas disponibilizam os folhetos doados pelo projeto para a comunidade escolar. Esta atitude demonstra a responsabilidade e preocupação de incentivar seus alunos à prática da leitura. Mesmo sem a presença de alguém qualificado na biblioteca e, na maioria das vezes, este espaço se encontrar fechado. Professores têm a iniciativa de mediar o contado com os livros.

Como constatado na pesquisa, $84,6 \%$ das escolas mantêm a coleção de cordéis e 15,4\% não têm folhetos em seu acervo. Isto demonstra, apesar de ser um percentual baixo, que é preciso ter responsabilidade para manter os materiais que são doados à escola. Aqui, é o caso dos cordéis que foram doados pelo Ministério da Cultura.

Constatou-se também que $100 \%$ das escolas desenvolvem alguma atividade didática com o folheto de cordel.

Observou-se que os folhetos de cordel são adquiridos pela maioria das escolas $(76,9 \%)$ para realização das atividades paradidáticas. Com esta iniciativa, a escola valoriza a cultura popular e também incentiva a leitura.

Os dados coletados demonstraram que o folheto de cordel é importante para o incentivo à leitura. Através dos folhetos são realizadas as seguintes atividades: leitura, interpretação de textos, estudo da gramática, poesia e história da literatura de cordel.

A disseminação dos materiais adquiridos pela escola para professores e alunos é importante para o estímulo e aprendizado da comunidade escolar. 


\section{CONSIDERAÇÕES FINAIS}

Desenvolver um trabalho de pesquisa que envolva a literatura de cordel foi um prazer pelo fato de saber que não apenas o método científico o conduzirá, mas também a poesia. O projeto "Cordel no espaço escolar" abriu portas e renovou a didática de ensino de muitos professores. As escolas, por mais simples que seja a atividade desenvolvida, têm, em seu programa de ensino, trabalhos realizados a partir dos folhetos de cordel.

A proposta de bibliotecas bem estruturadas com profissionais bibliotecários atuando junto a professores, para o desenvolvimento de projetos que envolvam a literatura de cordel e outras atividades realizadas pela escola ainda é algo distante das escolas públicas de João Pessoa. O acervo e espaço físico também precisam corresponder às necessidades de uma biblioteca. A resposta para esta indagação está na falta de políticas públicas que tem contribuído para ausência de bibliotecários nas escolas, pois a existência de bibliotecários poderá contribuir positivamente para o desenvolvimento intelectual da comunidade escolar.

A biblioteca escolar é peça fundamental na construção do conhecimento. Seu alicerce precisa ser firmado verdadeiramente na instituição chamada escola. É preciso que todos que compõem a comunidade escolar direcionem o olhar para o que é essencial, o coração da escola que é a biblioteca escolar. Não se pode imaginar que é apenas um lugar onde guarda livros e materiais para consulta, mas sim um ambiente que abriga respostas para suas dúvidas, que instiga a criatividade e que tem o objetivo de aumentar seus conhecimentos.

Bibliotecários e professores precisam abraçar a causa da biblioteca escolar, pois todos são responsáveis por esta unidade de informação - diretores, órgãos do governo e empresários. Estes dois últimos ainda precisam despertar para a importância da biblioteca escolar. Só poderemos ter um país desenvolvido intelectualmente, quando diversos espaços como - shopping, aeroportos, rodoviárias, hospitais, as grandes empresas, praças, órgãos públicos e inclusive a escola possuírem bibliotecas com profissionais formados para a função. Um dos suportes que não poderá faltar nestes espaços são os cordéis. Eles atraem pelo título e pela capa. O leitor sente a curiosidade de ler só de imaginar a história que o folheto irá narrar. Com a disseminação das bibliotecas em vários espaços, 
poderemos então escrever um novo conceito de educação e esta sim com acesso a informação.

O cumprimento da Lei ํㅜ 12.244/10 ainda há muito por se fazer. As escolas representadas por seus gestores continuam adormecidas, não acordaram para a conquista de se ter uma biblioteca e um profissional bibliotecário para gerir este espaço. Há urgência para a realização desta lei, que comece a mobilização pelos Bibliotecários, Associações, Conselhos Regionais e Federais e principalmente os Sindicatos. À medida que cada um fizer sua parte, seremos mais fortes e conquistaremos o apoio também da sociedade.

É importante que a escola, em parceria com a biblioteca, incentive seus alunos a participarem de concursos literários e de redação. Realizar miniconcursos para encorajar e motivá-los a participar. Fortalecer e aperfeiçoar a leitura e a escrita dos diversos gêneros textuais. Não se fixar apenas nos livros didáticos. A troca de informações entre alunos, professores, diretores e bibliotecários, acarretará em benefícios que serão de utilidades para todos.

Com as visitas realizadas nas escolas, alguns diretores destacam o empenho dos alunos na realização das atividades promovidas pela escola. Então, o que falta são as escolas apresentarem à comunidade escolar suas propostas e delegar funções para seus alunos, para que estes desenvolvam suas habilidades e contribuam para o crescimento e sucesso da escola e, consequentemente, deles próprios. A confiança que os professores colocam em seus alunos, ao permitir que eles possam expor suas habilidades e conhecimentos, os tornam pessoas autoconfiantes e que acreditam em suas potencialidades. Os comentários e opiniões dos respondentes acerca do projeto "Cordel no espaço escolar" serviram de embasamento para projetos futuros e, consequentemente, o aprimoramento das ideias e propostas para os próximos projetos.

Desenvolver uma pesquisa acerca de um projeto cujo objetivo maior foi incentivar a leitura tornou-se a realização perfeita. $O$ curso de biblioteconomia que tem como uma de suas funções mais importantes fazer a mediação entre informação e leitor abriu as portas e deixou o projeto "Cordel no Espaço Escolar" contar sua história de determinação para promoção, acesso e uso da informação, contida nos folhetos de cordel.

Com aplicação do questionário para coleta dos dados e, após a análise dos resultados, identificou-se que o projeto "Cordel no Espaço Escolar", teve forte 
influência no incentivo à leitura. Despertou nos professores e alunos a importância para valorização da cultura, ao deixar em cada escola a riqueza cultural que representa o cordel e as inúmeras atividades que podem ser realizadas com este suporte.

O impacto que o projeto "Cordel no espaço escolar" causou às escolas foi o contato dos alunos, dos professores e toda a comunidade escolar com a literatura de cordel em atividades didáticas.

\section{REFERÊNCIAS}

ALBUQUERQUE, M. E. B. C. de. Literatura popular de cordel: dos ciclos temáticos à classificação bibliográfica. 2011. 322 f. Tese (Doutorado em Letras) Universidade Federal da Paraíba, João Pessoa, 2011.

ALMEIDA, W. R.; COSTA, W. A. da; PINHEIRO, M. I. da S. Bibliotecários mirins e a mediação da leitura na biblioteca escolar. Revista ACB: Biblioteconomia em Santa Catarina, Florianópolis, v.17, n.2, p. 472-490, jul./dez. 2012.

ALVES, R. M. Literatura de cordel: por que e para que trabalhar em sala de aula. Revista Fórum Identidade, Sergipe, a. 2, n. 4, p. 103-109, jul./dez. 2008.

ARAÚJO, P. C. de; SALES, F. de. O bibliotecário e a formação de leitores. Revista ACB: Biblioteconomia em Santa Catarina, Florianópolis, v. 16, n. 2, p. 562-578, jul./dez. 2011.

BARRETO, A. de A. A questão da informação. Revista São Paulo em Perspectiva, Fundação Seade, v.8, n.4, 1994. Disponível em:

<http://aldoibct.bighost.com.br/quest/quest2.pdf >. Acesso em: 03 dez. 2013.

BRASIL. Ministério da Cultura. 26 de MINC. 2011. Disponível em: < http://www2.cultura.gov.br/site/2011/03/15/26-anos-do-minc/>. Acesso em: 05 jan. 2014.

Presidência da República. Lei 12.244 de 24 de maio de 2010. [Brasília, DF], 2010. Disponível em: <http://www.planalto.gov.br/ccivil_03/_Ato20072010/2010/Lei/L12244.htm>. Acesso em: 19 nov. 2013.

CAMPELLO, B. Como o estudante constrói significados da biblioteca escolar. In:__. Biblioteca escolar: conhecimentos que sustentam a prática. Belo Horizonte: Autêntica, 2012. p. 35-55. 
CASTRO FILHO, C. M. de; COPPOLA JUNIOR, C. Biblioteca Escolar e a lei 12.244/2010: caminhos para a implantação. Bibl. Esc. em R., Ribeirão Preto, v.1, n.1, p.30-41, 2012.

COBIAN, M. B.; COSTA, M. F. de L.; PINTO, M. I. R. Trabalhando com literatura de cordel no ensino fundamental: relato de uma vivência. Soletras, São Gonçalo: UERJ, ano 11, n. 21, p. 110-116, jan./jun. 2011.

DOMINGUES, P. Cultura popular: as construções de um conceito na produção historiográfica. História, São Paulo, v. 30, n. 2, p. 401-419, ago./dez. 2011.

FERREIRA, M. do C. S. B.; SANTANA, I. C. N. Biblioteca escolar: estratégias para torná-la mais atraente. In: CONGRESSO BRASILEIRO DE BIBLIOTECONOMIA, DOCUMENTAÇÃO E CIÊNCIA DA INFORMAÇÃO, 25., 2013, Florianópolis. Anais... Florianópolis, 2013. p. 1-5.

FONSECA, E. N. da. Introdução à Biblioteconomia. 2. ed. Brasília, DF: Briquet de Lemos, 2007, $152 \mathrm{p}$.

GAUDÊNCIO, S. M.; BORBA, M. do S. de A. O cordel como fonte de informação: a vivacidade dos folhetos de cordéis no Rio Grande do Norte. Biblionline, João Pessoa, v. 6, n. 1, p. 82-92, 2010.

GOIÁS. SECRETARIA DE ESTADO DA EDUCAÇÃO. Biblioteca escolar: uma ponte para o conhecimento. Maria Luiza Batista Bretas Vasconcelos (Org.). Goiânia: SEDUC, 2009. 112 p. Disponível em:

$<$ http://www.educacao.go.gov.br/documentos/reorientacaocurricular/fundamental/Bibl ioteca\%20Escolar.pdf>. Acesso em: 28 nov. 2013.

MACEDO, N. D. de (Org.). Biblioteca escolar brasileiro em debate: da memória profissional a um fórum virtual. São Paulo: SENAC; Conselho Regional de Biblioteconomia - 8 Região, 2005. 446 p.

MENEZES NETO, G. M. de. Literatura de cordel: recursos didáticos no ensino de história. Belém, PA: [s.n.], 2008. 11 p.

MILANESI, L. O que é biblioteca. São Paulo: Brasiliense, 1983. 108 p.

MORGÃO, D. R. Literatura de cordel: cocanha e a realidade nordestina. 2009. $78 \mathrm{f}$. Monografia (Graduação em Letras) - Universidade Federal do Rio Grande do Sul, Porto Alegre, 2009.

MUNHOZ, D. P. et al. O bibliotecário enquanto agente cultural: promovendo a leitura por meio de ações recreativas. Biblos, Rio Grande, v. 1, n. 1, p. 9-16, 2010.

PEREIRA, A. K. Biblioteca na escola. Brasília: Ministério da Educação, Secretaria de Educação Básica, 2006. 57 p. 
PINTO, A. de M.; OLIVEIRA, L. L. A. Biblioteca escolar e a educação no Brasil. In: CONGRESSO BRASILEIRO DE BIBLIOTECONOMIA, DOCUMENTAÇÃO E CIÊNCIA DA INFORMAÇÃO, 25., 2013, Florianópolis. Anais... Florianópolis, 2013. p. 1-11.

RIBEIRO, V. M. (Coord.). Indicadores da Qualidade na Educação: dimensão ensino e aprendizagem da leitura e escrita. São Paulo: Ação Educativa, 2006, 20 p.

RODRIGUES, C. S. D. Nos versos do cordel: as experiências de leitura dos estudantes do curso de pedagogia da URCA. In: ENCONTRO NACIONAL DE DIDÁTICA E PRÁTICAS DE ENSINO, 26., 2012, Campinas. Anais... Campinas: UNICAMP, 2012. p. 1-12

RUSSO, M.; SOUZA, D. de J. Biblioteca escolar brasileira na sociedade da informação: uma parceria proativa entre bibliotecário e pedagogo em prol da aprendizagem, da competência em informação e da quebra de paradigmas. In: CONGRESSO BRASILEIRO DE BIBLIOTECONOMIA, DOCUMENTAÇÃO E CIÊNCIA DA INFORMAÇÃO, 25., 2013, Florianópolis. Anais... Florianópolis, 2013. p. 1-16.

SILVA. F. I. C. da; SOUZA, E. D. de. Informação e formação da identidade cultural: o acesso à informação na literatura de cordel. Inf. \& Soc.: Est., João Pessoa, v. 16, n. 1, p. 215-222, jan./jun. 2006.

SILVA, J. L. C. Perspectivas históricas da biblioteca escolar no Brasil e análise da lei 12.244. Revista ABC: Biblioteconomia em Santa Catarina, Florianópolis, v. 16, n. 2, p. 489-517, jul./dez. 2011.

SILVA, J. S. da. Diáspora nordestina na baixada fluminense: a literatura de cordel como marca identitária. 2012. 129 f. Dissertação (Mestrado em Letras) Universidade do Grande Rio, Duque de Caxias, RJ, 2012.

Title

The impact of the project "Cordel at the school area" at school libraries of João Pessoa-PB

\section{Abstract}

Introduction: The stimuli on reading and on dissemination of Cordel Literature were the main aspects which have prompted the work on the project "Cordel at the School Area".

Purpose: to diagnose the impact caused by the project at libraries or reading rooms of public schools of João Pessoa-Paraíba.

Methodology: The applied method was of the quali-quantitative kind, taking into account the qualitative aspects - connected with researcher's reflexivity and respondents' opinions - as well as the quantitative ones, since that percentages which have been gotten by means of a questionnaire were examined. The work's corpus was formed by fifty schools that have been benefitted by the donation of cordel leaflets. As for the sample, sixteen schools at Cristo 
Redentor suburb were selected. As for the research technique for data gathering, a questionnaire was applied.

Results: It has been perceived that teachers have worked the cordel leaflets in the classroom, besides developing several activities rather than only the reading stimulus.

Conclusions: It was perceived that the project "Cordel at the School Area" has exerted great influence on the reading encouragement. Moreover, it has awaken both teachers and students to the importance of taking culture for granted, once it has taken to each school the cultural force represented by Cordel Literature and numberless didactic activities that can be developed with such a support.

Key words: School Library. Cordel Literature. Reading Encouragement.

\section{Título}

El impacto del proyecto "Cordel en el espacio escolar" en las bibliotecas escolares de João Pessoa-PB

\section{Resumen}

Introducción: El incentivo a la lectura y la disseminación de la Literatura de Cordel fueron los principales aspectos que han motivado el trabajo con el proyecto "El Cordel en el Espacio Escolar".

Objetivo: Diagnosticar el impacto causado por el proyecto en las bibliotecas o salas de lectura de las escuelas públicas de la ciudad de João Pessoa-Paraíba.

Metodología: Se utilizó el método quali-quantitativo, considerando los aspectos qualitativos - como la reflexividad del investigador y las opiniones de los encuestados - cuanto a los aspectos quantitativos por verificar los porcentajes obtenidos a través de la aplicación del cuestionario. El corpus del trabajo fue constituído por cincuenta escuelas que fueron beneficiadas con la donación de los cordeles. Como muestra, fueron seleccionadas dieciséis escuelas del barrio el Cristo Redentor. Como técnica de investigación para la recolección de los datos, se utilizó el cuestionario.

Resultados: Se constató que los maestros trabajaron los cordeles en clase y desarrolaron varias actividades además del incentivo a la lectura.

Conclusiones: Se identificó que el proyecto "Cordel en el Espacio Escolar" tuve fuerte influencia en el incentivo a la lectura. Despertó en los maestros y alumnos la importancia para la valorización de la cultura, al dejar en cada escuela la riqueza cultural que representa el cordel y las incontables actividades didácticas que pueden ser realizadas con este soporte.

Palabras clave: Biblioteca Escolar. Literatura de Cordel. Incentivo a la Lectura.

Recebido em: 14.06.2014

Aceito em: 07.04.2015 